\title{
The North Pacific Storm-Track Suppression Explained From a Cyclone Life-Cycle Perspective: Supplementary Material
}

Sebastian Schemm ${ }^{1}$, Heini Wernli ${ }^{1}$, and Hanin Binder ${ }^{1}$

${ }^{1}$ Institute for Atmospheric and Climate Science, Universitätstrasse 16, 8092 Zürich, Switzerland

Correspondence: sebastian.schemm@env.ethz.ch

Abstract. Supplementary Material

- Lagged-composite of 300-hPa geopotential anomalies preceding Kuroshio cyclogenesis. 
Kuroshio Cyclogenesis

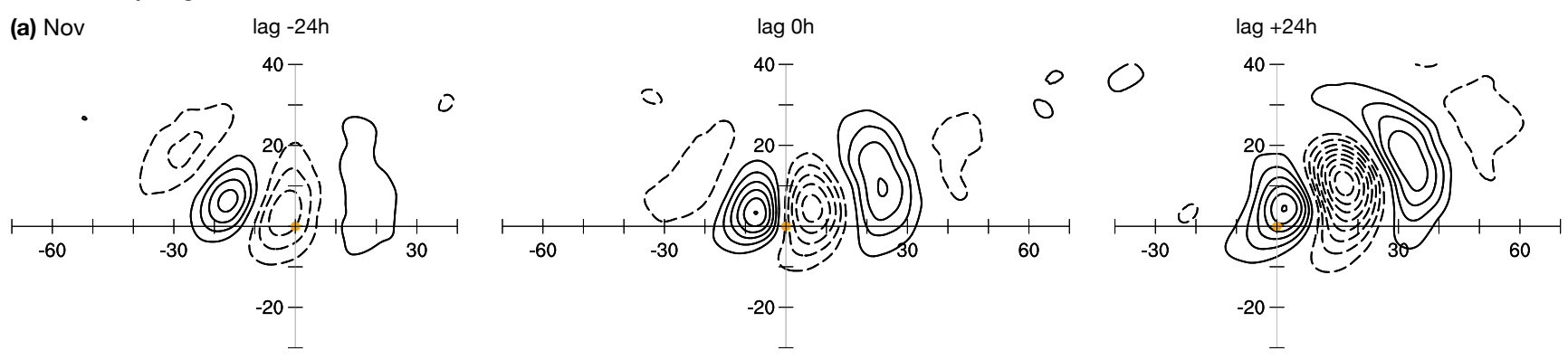

(b) Jan
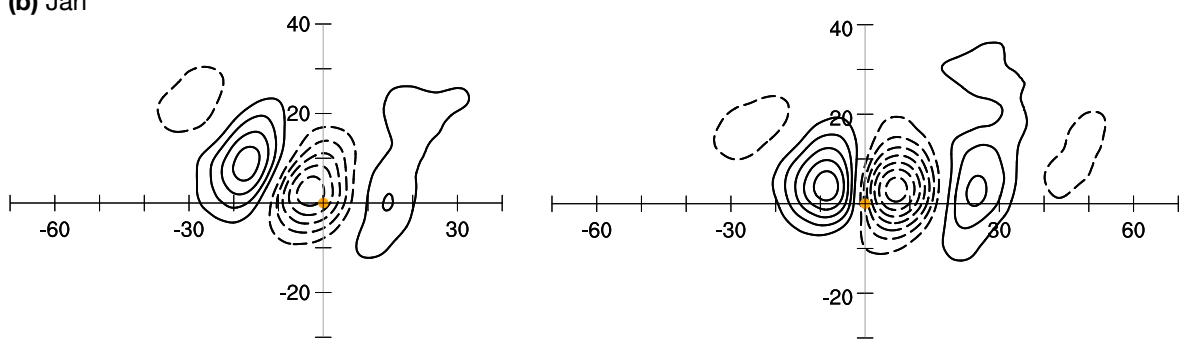

$-20-$

(c) Mar

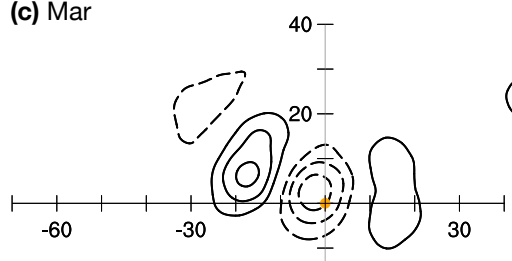

$-20-$

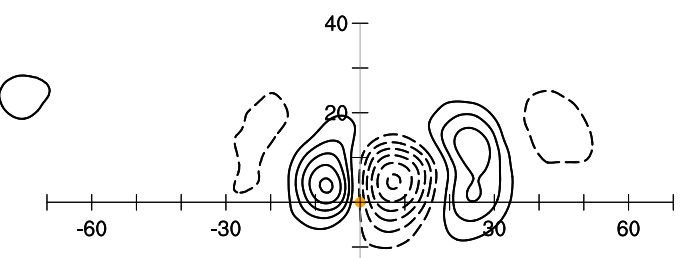

$-20-$

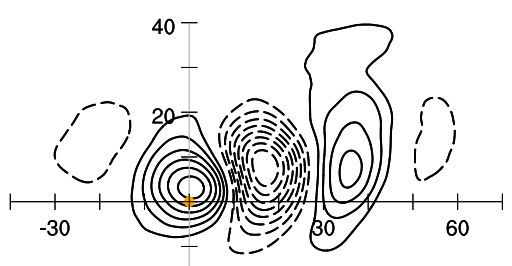

$-20-$

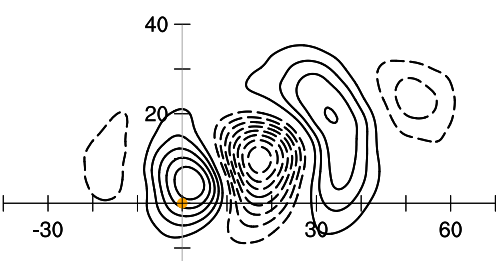

$-20-$

Figure S1. Composites of 300-hPa geopotential anomalies (first column) one day before, (second column) at and (third column) 24 hours after Kuroshio cyclogenesis during (first row) November, (second row) January and (third row) March. Solid contours correspond to an upperlevel trough (negative geopotential anomalies) and dashed contours correspond to an upper-level ridge (positive geopotential anomalies). 